\title{
CONSUMO NA AMÉRICA LATINA E NORMATIZAÇÃO DO COMÉRCIO JUSTO: DA FORMAÇÃO DE REDES À POLÍTICA PÚBLICA
}

\author{
EL CONSUMO EN AMÉRICA LATINA Y LA NORMALIZACIÓN DEL COMERCIO \\ JUSTO: DE LA FORMACIÓN DE REDES A LA POLÍTICA PÚBLICA
}

${ }^{1}$ Everton das Neves Gonçalves

2Joana Stelzer

\begin{abstract}
RESUMO
Os Estados latino-americanos perante os efeitos danosos promovidos pelo neoliberalismo testemunharam o consumismo e o superendividamento dos consumidores. A situação é resultado das políticas de livre comércio internacional e da influência de grupos de interesse que atuam nessa região. Na qualidade de contra movimento tem-se o Comércio Justo, modalidade de troca que visa ao estabelecimento de preços justos, padrões de sustentabilidade equilibrados nas cadeias produtivas, promovendo produtores responsáveis e consumidores éticos. No âmbito da sociedade civil, colabora o fenômeno da formação das redes de colaboração solidária. Tendo em vista tal realidade, o objetivo geral da presente investigação consistiu em avaliar o consumo latino americano por intermédio do Comércio Justo e a importância da formação das redes, apresentando-se, ao final, a proposta brasileira por intermédio de política pública. Os objetivos específicos, por sua vez, descreveram o sistema comercial tradicional, apresentaram o Comércio Justo e o consumo responsável, identificaram as redes de Comércio Justo na América Latina e a regulamentação do Estado brasileiro sobre o assunto. O método utilizado foi o crítico indutivo, avaliando-se os dados e as informações sob forma qualitativa. Os meios utilizados foram exclusivamente bibliográficos. Quanto aos fins, a pesquisa apresenta-se de cunho descritivo e os resultados foram expostos em forma de textos.
\end{abstract}

Palavras-chave: Comércio justo, Consumismo, Fair trade, Teoria das redes, América latina

\footnotetext{
${ }^{1}$ Doutor em Direito pela Universidade Federal de Minas Gerais - UFMG, Minas Gerais (Brasil). Professor de Direito pela Universidade Federal de Santa Catarina - UFSC, Santa Catarina (Brasil) E-mail: evertong@ vetorial.net

${ }^{2}$ Doutora em Direito pela Universidade Federal de Santa Catarina - UFSC, Santa Catarina (Brasil). Professora pela Universidade Federal de Santa Catarina - UFSC, Santa Catarina (Brasil)

E-mail: contatojoana@yahoo.com.br
} 


\section{RESUMEN}

Los estados latinoamericanos frente a los efectos perjudiciales causados por el neoliberalismo presenciaron el consumismo y el sobreendeudamiento de los consumidores. La situación es el resultado de las políticas de libre comercio internacional y la influencia de los grupos de interés que trabajan en esta área. Como contra movimiento ha aparecido el Comercio Justo, modalidad de comercio que tiene como objetivo establecer precios justos, estándares de sustentabilidad equilibradas en las cadenas productivas, para promover productores responsables y consumidores éticos. Dentro de la sociedad civil, colabora el fenómeno de la formación de redes de colaboración solidarias. Ante esta realidad, el objetivo general de este estudio fue evaluar el consumidor latinoamericano por el Comercio Justo y la importancia de la formación de redes, presentando, al final, la propuesta brasileña a través de las políticas públicas. Los objetivos específicos, a su vez, mostraron el sistema de comercio tradicional, detallaron el comercio justo y el consumo responsable, presentaron las redes de Comercio Justo en América Latina y la regulación del gobierno brasileño sobre el tema. El método utilizado fue el inductivo crítico, evaluando los datos y la información de una manera cualitativa. Los medios utilizados fueron exclusivamente de carácter bibliográfico. En cuanto a la finalidad, la investigación presenta la naturaleza descriptiva y los resultados se muestran en forma de textos.

Palabras-claves: Comercio justo, Consumismo, Fair trade, Teoría de redes, América latina 


\section{Introdução}

O comércio sustentável para a América Latina é uma realidade que se faz possível por diversos caminhos econômicos, fazendo com que as práticas de consumo decorrentes se tornem viáveis a partir da formação da sociedade em redes de colaboração solidária, especialmente por intermédio do Comércio Justo (Fair Trade). A América Latina, contudo, tem confessado uma realidade diferente. A impotência dos Estados diante da rapinagem que o neoliberalismo injetou na região, deflagrou o consumismo e o superendividamento da população. A situação não é resultado do acaso. Com efeito, decorre da ação concertada da instalação de grupos de interesse e de Corporações Transnacionais atuantes no âmbito do comércio mundial tradicional, que induzem um necessário comportamento por parte do Estado, dos consumidores e dos credores para que seja coerente com suas necessidades e possibilidades de expansão. Como tudo isso ocorrer irá depender da situação econômica, social e política do respectivo país. Contudo, o que interessa mesmo é a forma de controlar aquela sociedade.

O Fair Trade representa um contramovimento a esse processo, envidando esforços para importar, exportar, distribuir e comercializar produtos oriundos de países em desenvolvimento (ou mesmo para valorizar produtos internos desses países), no intuito de alterar injustas estruturas do comércio mundial. Na outra ponta do processo de Comércio Justo estão possíveis consumidores, enquanto sujeitos ativos que podem impulsionar a relação negocial de forma sustentável à medida que a consciência política permite exercitar a escolha entre produtos oriundos do comércio tradicional e do Comércio Justo. No âmbito do Fair Trade, o consumidor pode transformar o ato de consumo em ato político de inclusão social. Para isso, deve estar presente a liberdade de opção por parte do consumidor, que deve ter o direito de optar entre a comercialização ordinária e a comercialização que perpassa a justiça social. Essa liberdade pode o Estado facilitar ao viabilizar políticas públicas de Comércio Justo em seu território (e que conviverá com a organização política do terceiro setor que investe esforços para articular a sociedade civil).

Do exposto, a problematização consiste em descrever as possibilidades de Comércio Justo na América Latina enquanto alternativa para minimizar o consumismo, levando em consideração a capacidade de organização da sociedade em redes de colaboração solidária perante a ausência de políticas públicas que estimulem a comercialização com justiça social, em que pese a iniciativa brasileira. Com efeito, apresenta-se - brevemente - a proposta brasileira de política pública para o Comércio Justo, em fase de implementação. Entre as 
teorias que se apresentam para explicar a vulnerabilidade de mercado destacou-se a Teoria de Dependência de Raul Prebisch e da Escola Cepalina, com destaque também para o pensador chileno Fernando Fajnzylber sobre o relacionamento existente com as Corporações Transnacionais (CTNs). No âmbito da Teoria das Redes, o referencial teórico utilizado teve por fundamento André Euclides Mance e Manuel Castells. Quanto ao Fair Trade, usufruiu-se dos estudos de Fretel e Simoncelle-Bourque, Frans Van der Hoff e Rosemary Gomes, além de sites institucionais de organizações de apoio ao Comércio Justo.

A investigação justifica-se em virtude de muitos estudos no âmbito do consumismo estarem desassociados das condições que são impostas pelo mercado e não evitadas por políticas públicas, no âmbito da globalização econômica e, especialmente, na América Latina. Permitese, assim, fazer um estudo panorâmico do sistema comercial tradicional e da vulnerabilidade do consumidor, considerando de forma mais específica o Comércio Justo e a formação de redes na América Latina para estimular o consumo responsável.

Tendo em vista tais apontamentos, o objetivo geral da presente investigação consistiu em avaliar o consumo latino americano por intermédio do Comércio Justo e a importância da formação das redes, apresentando-se, ao final, a proposta brasileira por intermédio de política pública. Os objetivos específicos que permitiram o alcance do objetivo geral foram: descrever o sistema comercial tradicional e sua relação com as práticas consumeristas latinoamericanas; apresentar o Comércio Justo e o consumo responsável, trazendo o histórico e os apontamentos conceituais; evidenciar a incapacidade do Estado para evitar a vulnerabilidade do mercado e o contramovimento presente na mobilização dos consumidores em redes de colaboração; e, identificar destacadas redes de Comércio Justo na América Latina e a regulamentação do Estado brasileiro sobre o assunto.

O método utilizado foi o crítico indutivo, avaliando-se os dados e as informações sob forma qualitativa. Os meios utilizados foram exclusivamente bibliográficos e foram coletados por três fontes secundárias de informação: relatórios institucionais, legislação e produção científica de reconhecidas obras doutrinárias. Quanto aos fins, a pesquisa apresenta-se de cunho descritivo e os resultados foram expostos exclusivamente em forma de textos.

\section{Sistema comercial tradicional e sua relação com práticas consumeristas: breve histórico latino-americano}

O consumo na América Latina revela um elevado ritmo de expansão nas últimas décadas, dinamismo que nem sempre está ligado ao bem-estar da população, pois traz 
externalidades negativas, como o consumismo desenfreado (e acrítico), além do superendividamento. O fenômeno não pode ser atribuído exclusivamente ao comportamento do consumidor, pois está aliado a ausência de políticas públicas que inibam o modelo neoliberal de mercado. Em síntese, percebe-se que o Estado participa do sistema comercial tradicional sem defender a população dos efeitos maléficos das grandes quantidades e das magnitudes. Para que não se caia em uma degradação profunda e irreversível desse modelo, faz-se necessária a valorização de emergentes padrões comerciais, como o Comércio Justo, resgatando brevemente as teorias desenvolvimentistas. Não se trata de uma discussão voltada sobre o comércio internacional, mas, de como seus princípios e regras precisam ser filtrados pelo Estado, para que os valores neoliberais não se instalem sem nenhuma resistência.

A cooperação comercial internacional entre os países em desenvolvimento originase, formalmente, na concepção da UNCTAD, em 1964. As idéias tinham forte influência de seu primeiro Secretário-Geral, o economista argentino Raul Prebisch, que, já no âmbito da Comissão Econômica para a América Latina e o Caribe (CEPAL), defendia a tese da substituição de importações, sob o escopo da Teoria da Dependência.

Ao inferir que se registrava uma forte tendência de aumentar a lacuna entre o centro industrializado e a periferia subdesenvolvida nas relações econômicas internacionais, Raul Prebisch concluiu que os países periféricos de economia agroexportadora deveriam implementar um amplo processo de substituição de importação, como única saída de se tornarem países industrializados. (OLIVEIRA, 2007, p. 116).

Ademais, o autor defendia também que uma das principais restrições para aumentar a poupança interna eram as imitações de consumo dos países avançados por parte das economias subdesenvolvidas. "Esse traço de consumo imitativo entre nações também foi ressaltado por Nurkse (1953) e posteriormente incorporado por diversos autores próximos da corrente cepalina (Celso Furtado, Fernando Henrique Cardoso, Enzo Faletto, Aníbal Pinto y Fernando Fajnzylber)" (CEPAL, 2015). Nesse ponto, deve emergir uma clara visão que o consumo privado está condicionado pelas instituições formais e informais de uma sociedade.

Ainda de acordo com a CEPAL (2015), em termos sócio-políticos isso significa que os choques macroeconômicos se transmitem quase sem atenuação ao consumo privado e, em última instância, às condições de vida da população. As características decorrentes são os impactos negativos sobre a coesão social e a confiança em instituições como o mercado, o sistema político ou o aparato do Estado. Além de estar influenciado diretamente pelos mercados, o consumo privado é afetado por normas que moldam a concorrência entre ofertantes de bens e serviços, e pela existência de um Estado de bem-estar que poderia amortizar os choques 
adversos, entretanto - na maior parte dos casos - não o faz. Esses fenômenos, conclui o estudo cepalino, podem provocar a expansão da oferta de cartões de crédito que se transformarão em armadilhas de endividamento para um grande número de consumidores (Thaler y Sunstein, 2008; Khaneman, 2011). "Com efeito, o cartão de crédito pode ser percebido pelos consumidores que não realizam uma análise racional e tem uma porta fácil ao consumo [...]; entretanto, depois a esses consumidores resulta difícil sair do endividamento".(CEPAL, 2015)

É preciso registrar que a visão econômica tradicional nega a necessidade de proteger o consumidor, sob o argumento que se trata de sujeito soberano e consciente para eleger com liberdade suas opções. Contudo, sob outra ótica, cumpre afirmar que a atual sociedade de consumo atrelada aos princípios do comércio internacional tradicional (Free Trade) acabam fixando metas de consumo inalcançáveis a vastas camadas da população que se submetem a tal lógica, arrastando-as à frustração e à perda crescente de sua autonomia financeira.

A concepção de uma proteção comercial externa por parte do Estado e dos próprios consumidores, destarte, representam duas vias que caminham juntas. O presente quadro deve ser avaliado sob dupla ótica: inicialmente, pela vulnerabilidade do Estado; e, após, pela ausência de políticas públicas internas que pudessem resguardar o consumidor, afinal, a "a cultura líquido moderna não tem 'pessoas' a cultivar, mas clientes a seduzir" (BAUMAN, 2010, p. 36).

\begin{abstract}
Chegamos ao momento em que a comercialização dos modos de vida não mais encontra resistências estruturais, culturais nem ideológicas, e em que as esferas da vida social e individual se reorganizam em função da lógica do consumo. A primeira e a segunda fase do consumo haviam tido como consequência a criação do consumidor moderno, arrancando-o às tradições e arruinando o ideal de poupança; a última fase estendeu ao infinito o domínio do consumo. (LIPOVETSKY, 2004, p. 31)
\end{abstract}

Com a aceleração do fenômeno da globalização econômica, os governos nacionais e - especialmente - os governos latino-americanos perceberam a fluidez dos recursos financeiros e a diminuição da capacidade local para gerenciar o Estado. Com isso, os países defrontaram-se com uma crônica vulnerabilidade externa, que apareceu como um elemento histórico-estrutural. As práticas de consumo, nesse ritmo, beiram ao absurdo.

Nesse ritmo, Brum (1999, p. 82) destaca que os Estados nacionais perderam parcelas de poder, quer ao integrar-se em organismos internacionais, quer perante as grandes Corporações Transnacionais, pois os governos não conseguiam tomar as grandes decisões econômicas. "Como o setor público, em geral, está endividado e enfrenta dificuldades financeiras, e os grandes grupos econômicos têm disponibilidade de capital, os governos 
promovem privatizações de empresas estatais e se esforçam para atrair empresas de capital estrangeiro para impulsionar o desenvolvimento, atentos ao aporte de tecnologia. Cada vez mais, são as poderosas corporações mundiais que decidem o que, como, quando, quanto e onde produzir e a quem vender.” (BRUM, 1999, p. 49) A Revista Infomoney (2015), ao publicar matéria sobre as dez tendências de consumo na América Latina, informa que uma marca de roupa lançou uma campanha na Costa Rica que auxiliava os consumidores que estivessem em situação de 'emergência de moda' a entrar na moda imediatamente. "A campanha permitiu que 100 clientes pedissem a visita de um caminhão de roupas e acessórios para ajudá-los". (INFOMONEY, 2015)

Sob a tendência de mercado, ganhou espaço a teoria da interdependência, apesar de a visível disparidade entre países ricos e pobres no cenário externo, não amenizado pela cláusula do tratamento diferenciado e mais favorável que deveria ser concedido pelos países desenvolvidos, conforme estabeleciam as regras da OMC. Os benefícios que poderiam advir por intermédio dos artigos XXXVI e XXXVIII, do Tratado GATT (General Agreement on Tariffs and Trade) foram aguardados na Rodada de Doha (Qatar) em 2001, mas, não obtiveram êxito. Nessa conferência, os países procuraram seguir o compromisso único (single undertaking), levando em conta o princípio da Plena Participação de Países em Desenvolvimento.

A tentativa de incrementar o comércio Sul-Sul e mesmo o latino americano, por outro lado, não esgotava a questão comercial que os países em desenvolvimento mantinham com os países desenvolvidos, pois é relevante destacar que o maior volume de transações continuava sendo feito com as nações abonadas. Sob outro foco, o relançamento do Sistema Geral de Preferências Comerciais entre países em desenvolvimento (SGPC) também poderia ser apontado como uma alternativa real para estimular essas negociações. O SGPC no Brasil (Decreto Legislativo $\mathrm{n}^{\circ}$ 98, de 25/03/91) objetivava funcionar como instância de concessões comerciais entre os membros do G 77, que congregava países (ditos) pobres (atualmente com 132 membros) e lutava por justa liberalização do comércio mundial desde o surgimento da UNCTAD. De acordo com Arbix (2002, p. 17), as “[...] experiências mais exitosas desmitificam a idéia de que haveria um caminho único e seguro para o desenvolvimento".

O progresso nas discussões comerciais entre países do SGPC e a ampliação dos Estados-membros acabou fracassando, embora tivessem sido endossados pelo Consenso de São Paulo e pelo Espírito de São Paulo, documentos que compuseram as declarações finais da XI UNCTAD, realizada no Brasil, em 2004. Nesse sentido, o parágrafo 8 do Consenso de São Paulo ilustrara a interdependência existente entre os avanços do comércio internacional e as 
regras institucionalizadas. Em algumas situações, tinha-se a impressão de encontrar os caminhos para resolver as graves dificuldades que assolavam a humanidade, mas, jamais foram trilhados os rumos então apontados.

[...] Cabe a cada governo avaliar o peso dos benefícios de aceitar regras e compromissos internacionais e as limitações colocadas pela perda do espaço para políticas. É particularmente importante para os países em desenvolvimento, tendo em mente as metas e objetivos de desenvolvimento, que todos os países levem em conta a necessidade de equilíbrio apropriado entre o espaço para políticas nacionais e as disciplinas e compromissos internacionais.(UNCTAD, 2015a)

Naquela ocasião, o documento de trabalho denominado Espírito de São Paulo - de cunho político -, afirmara que "é preciso centrar a atenção na capacidade de liberalização do comércio para contribuir para o alívio da pobreza". (UNCTAD, 2015b) Em matéria de inserção internacional, portanto, a idéia de crescimento não deveria ficar atrelada singelamente ao aumento absoluto na participação das trocas mundiais. O comércio Sul-Sul e latino americano, além de sugerir maior intercâmbio, deveria traduzir-se também em estratégia segura de desenvolvimento, apoiando esforços que promovessem justiça social e desfizessem graves deficiências internas. Como já se sustentou, por décadas aguardava-se que a compatibilidade e efetividade de atuação das esferas OMC e UNCTAD (United Nations Conference on Trade and Development) trouxessem novas oportunidades de negócio para vastas camadas da população mundial. Dessa realidade, verificou-se a dificuldade do Estado em traçar políticas de comércio internacional seguras para o consumidor.

Com isso, decorreram também políticas inconsistentes de consumo. Sob tal ótica, o Código do Consumidor (de 1990) acabou por resultar também da incapacidade do Estado em lidar com as forças de comércio (e, principalmente, do consumo) que se alastravam sobre a população. Antes mesmo de proteger o consumidor das relações nas quais se envolveu e nas quais o Código viria a ser útil, deveria o Estado ter precavido o consumidor, não o deixando tão vulnerável e exposto perante o sistema de comércio internacional.

A imposição dos valores de mercado dos países considerados centrais e a relação de fragilidade com países em desenvolvimento não é diferente quando o assunto é a instalação de Corporações Transnacionais. Com efeito, a empresa recorre a países considerados vulneráveis e planeja não somente suas operações, mas, o comportamento da população (consumidor) e do governo em tudo aquilo que possa lhe dizer respeito. A atenção das empresas, portanto, não se "concentra exclusivamente em sua eficiência econômica e técnica, pois para que isso seja possível é preciso que se desenvolva uma ação externa que induza um comportamento 
por parte do Estado, dos consumidores, dos credores e dos fornecedores, que seja coerente com seus objetivos e potencialidades de expansão." (FAJNZYLBER, 2015, p. 9).

Nesse ponto, esclarece Fajnzylber (2015), é preciso frisar que o grau no qual isso vai se tornar possível vai depender das condições econômicas, sociais e políticas do respectivo país e, o que importa, é o meio no qual a Corporação Transnacional (CTN) vai atuar viabilize sua expansão. É preciso, nesse sentido, que o Estado aprove a sociedade de consumo, viabilizando às empresas o necessário incentivo para que os consumidores comprem. Além disso, é preciso que esteja presente a capacidade efetiva para aquisição das mercadorias comparável às expectativas de produção da CTN. Os resultados que os países latinos colheram dessa realidade foram o consumo excessivo e um grave endividamento. O Relatório da CEPAL (2015), finalmente, esclarece que o comportamento do consumo das famílias com renda mais baixa está profundamente influenciado pela sorte da norma social.

\footnotetext{
Os padrões emulativos de consumo e outros fatores poodem induzir aos consumidores - de forma ocasional ou regular - a buscar níveis de consumo superiores aos seus ingressos, exigindo capacidade de obtenção de crédito. Essa obtenção pode possibilitar resultados valiosos, como a aquisição de bens de alto custo [...] mas, dependendo dos níveis e das taxas de juros as famílias podem cair em armadilhas de endividamento e chegar a contrair dívidas para pagar dívidas. (CEPAL, 2015, p. 311)
}

As chances de mobilização e de esforços conjuntos, em verdadeiro processo de contramovimento, contudo, existem e se processam por intermédio de redes. Em decorrência do novo cenário que a realidade transnacional desenha, não somente das cúpulas governamentais se esperam soluções, mas de entidades da sociedade civil, produtores e consumidores que podem fazer mais por si mesmas, dentre as quais as opções de Comércio Justo (Fair Trade) e consumo responsável.

\section{Comércio Justo e Consumo Responsável: histórico e apontamentos conceituais}

O Comércio Justo (Fair Trade) representa um movimento transnacional preocupado com a promoção de condições de mercado mais justas, seja entre países consumidores desenvolvidos e países produtores em desenvolvimento; seja também entre países em desenvolvimento, tanto na qualidade de consumidores, quanto produtores (ou, ainda, internamente, nos países em desenvolvimento). "Trata-se de um movimento social e uma modalidade de comércio internacional que busca o estabelecimento de preços justos, bem como de padrões sociais e ambientais equilibrados nas cadeias produtivas, promovendo o encontro de produtores responsáveis com consumidores éticos" (COTERA; ORTIZ, 2009, p. 
$60)$.

Alguns autores apontam o começo do Comércio Justo no movimento hippie nos anos 60. Com base nos protestos e nos movimentos que clamavam por alterações sociais e políticas, acabaram levando a um novo tipo de comportamento e, principalmente, mudanças em relação ao consumo. "Trata-se de um novo modo de pensar e de enxergar a realidade que levou esses grupos a exigir práticas comerciais que não exploram pequenos grupos, comunidades inteiras e até mesmo países onde o único meio de sobrevivência vem de seus recursos naturais e da mão de obra de seus habitantes". (MENDES; FERREIRA, 2013, p.

124), sendo também compreensível como "uma prática comercial baseada na eficiência econômica, sustentabilidade social e sustentabilidade ecológica [...] o Comércio Justo não é uma capitulação ante a ideologia do mercado". (VAN DER HOFF, 2003, p. 242-243)

O início da comercialização de forma institucionalizada, por sua vez, não é pacífica. Em verdade, existiam ações semelhantes dispersas que somente com a globalização ganhou unicidade de propositura. Prata (2015) esclarece que o movimento tem nascimento histórico por volta da metade do século passado na Europa e nos EUA quando ganhou força a concepção de tornar o comércio uma fonte de recursos e inclusão social para comunidades empobrecidas de países em desenvolvimento.

A ideia era que fosse possível incluir pequenos produtores no mercado internacional, no anseio de minimizar a pobreza no hemisfério sul. Na visão de Frans Van Der Hoff $(s / d)$, o comércio justo deve servir - acima de tudo - como um indicativo de mudança do sistema comercial, pois o combate à pobreza - segundo o autor - chega a ser um equívoco:

[...] a pobreza é um produto que recai sobre pessoas que se chamam pobres. Primeiro, produzem-se pobres e depois se alivia a pobreza ou se combate. É um mundo ao contrário. A tarefa que consiste em combater um sistema que produz pobreza: organização, mercado diferente, lobby sobre e com as instâncias internacionais, ser parte do movimento de um mundo diferente, etc. (VAN DER HOFF, 2015)

Além desse aspecto, faz parte da lógica do Comércio Justo a responsabilidade, a ética e a solidariedade do consumo na qualidade de contraponto ao fenômeno, pois não existe Fair Trade se não se testemunharem consumidores conscientes no equilíbrio e na responsabilidade que implica o ato de consumo.

O movimento também foi um efeito à diminuição de empregos formais atrelada ao enfraquecimento do Estado de Bem-Estar Social, além da conscientização dos consumidores sobre o abismo social existente entre os povos, o uso de agrotóxicos no aumento da produção 
de alimentos e o crescimento da miséria mundial. Alguns estudiosos, entretanto, entendem que essa prática de inserção de produtos já era passível de visualização até mesmo em épocas mais remotas, pois nas missões cristãs que lideravam Organizações Não Governamentais (ONGs) na Europa e América do Norte constava-se a venda de artesanatos produzido por artesãos de países do Sul em mercados centrais.

$\mathrm{Na}$ Europa, os esforços pela promoção do comércio justo foram capitaneados pela Oxfam e por um grupo católico holandês. Atualmente, a Oxfam International é uma organização (em rede) com mais de 3000 parceiros e atuação em mais de 100 países na busca de soluções para o problema da pobreza e da injustiça. (OXFAM, 2014) Na América do Norte, o Fair Trade recebeu impulso da Mennonite Central Committee e por um programa da Igreja de Brethren. Nos anos 1950 e 1960 essas ONGs desenvolveram as denominadas North American Alternative Trade Organizations (NAATOs), articulando a importação e venda desse artesanato por intermédio de grupos de solidariedade da Igreja (BOSSLE, 2014, p. 20). Segundo a WFTO (2015), nos Estados Unidos o fenômeno teve início na Ten Thousand Villages (anteriormente Artesanato Auto-Ajuda) que começou a comprar bordados de Porto Rico, ainda em 1946. A primeira loja de Comércio Justo formal, vendendo esses e outros produtos, foi inaugurada em 1958 nos Estados Unidos (STELZER; GONÇALVES, 2015b)

\footnotetext{
O Comércio Justo recebeu um grande impulso no âmbito do comércio internacional por ocasião na conferência da UNCTAD de Nova Délhi, em 1968, sob o lema "Comércio, não ajuda". Com isso, encerrava-se o caráter caritativo para fazer com que o modelo de Fair Trade recebesse o status de justiça no sistema comercial. Naquela ocasião, algumas Organizações Não-Governamentais, a exemplo da Oxfam Internacional (Grã-Bretanha) e da Artisans du Monde (França), começaram a comercializar mercadorias adquiridas mediante comércio justo por intermédio de suas lojas. Com isso, relações comerciais justas entre os Hemisférios Sul e Norte seriam uma condição mais importante para o sucesso dos esforços desenvolvimentistas dos países do Sul do que se esses recebessem a clássica assistência para se desenvolverem. (STELZER; GONÇALVES, 2015b, p. 11)
}

Bossle (2014, p. 21-22) esclarece que nas décadas de 70 e 80 as redes de Comércio Justo receberam grande impulso, mas, o mercado (da rede) era muito pequeno para ajudar os produtores do Sul. Nesse momento, concluiu-se pela necessidade de inserção nos mercados tradicionais. A EFTA (European Free Trade Association), com sede na Holanda, também é uma organização internacional de destaque, que inclui dez importadores de Comércio Justo em nove países europeus (Suíça, Itália, Áustria, Holanda, Alemanha, Espanha, Bélgica, França e Reino Unido) (STELZER; GONÇALVES, 2015b). A EFTA foi criada informalmente em 1987, ganhando estatuto oficial em 1990 (EFTA, 2015). 
Fajardo (2010, p. 54) explica que o comércio justo se baseia na solidariedade econômica e financeira e não existem vencidos nem vencedores nas relações comerciais, pois se procura evitar que uma parte perca para que a outra possa ganhar. Quando todas as partes envolvidas ganham, a atividade comercial adquire um caráter mais igualitário e estimulante para quem a pratica. Fretel e Simoncelle-Bourque (2003. p. 19) evidenciam que se trata de um "intercâmbio comercial orientado para o reconhecimento e a valorização do trabalho e das expectativas dos produtores e consumidores, permitindo uma melhoria substancial na qualidade de vida das pessoas, tornando viável a vigência dos direitos humanos e o respeito ao meio ambiente numa perspectiva de desenvolvimento humano, solidário e sustentável". Trata-se, em síntese, no restabelecimento de relações saudáveis entre produtores e consumidores, ou seja, um retorno ao que deveria ser o normal: aquisição por necessidade, venda justa e relação solidária.

O Relatório Mundial de Comércio, editado pelo SEBRAE, explica que na Conferência anual da IFAT (International Federation of Alternative Trade), em 2001, houve a uniformização dos conceitos, ficando o Comércio Justo definido da seguinte maneira: "Comércio Justo é uma parceria comercial, baseada em diálogo, transparência e respeito, que busca maior equidade no comércio internacional. Ele contribui para o desenvolvimento sustentável por meio de melhores condições de troca e a garantia dos direitos para produtores e trabalhadores marginalizados - principalmente do Sul". (SCHNEIDER, 2015, p. 30). Para Van der Hoff (2003, p. 243), o Comércio Justo aproveita a liberdade de eleição do consumidor "para adiantar-se à integração do componente social e ecológico na política econômica mundial. O consumidor já pode eleger produtos cujos preços expressam a verdade acerca do custo real".

Mudanças nas regras e nas práticas do comércio internacional tradicional são as conquistas mais prementes, em virtude dos números que se apresentam: os 48 países menos desenvolvidos do mundo tiveram suas exportações diminuídas para $0,4 \%$ do total mundial nas duas décadas, enquanto Estados Unidos e União Europeia representam cerca de $50 \%$ do movimento mundial. (PORTALECOD, 2015).

\section{Comércio Justo: entre a incapacidade do Estado e a mobilização dos consumidores em redes de colaboração}

A produção do comércio mundial encontra-se internacionalmente organizada pela estratégias dos países centrais e por suas corporações que buscam formas de integração comercial e produtivas em grandes cadeias. Além dos elementos materiais que caracterizam 
essa articulação, fazem parte também as políticas públicas de países ditos periféricos que permitem a criação do substrato nacional para o florescimento dessa realidade em seu território, proporcionando a fragilização do consumidor perante a excessiva oferta de produtos, a compra desnecessária, a idolatria das marcas, enfim, aspectos da imitação de consumo. Paralelamente, como já se frisou, viabilizam-se também os meios de crédito necessários para sustentar a previsão de crescimento dessas empresas. Disso, resultou, entre outros, o consumo sem criticidade e o superendividamento.

Quando se pensa na relação consumerista, a ideia é que a proteção deveria decorrer exclusivamente da lei, especialmente de um Código. Contudo, defende-se a concepção que o consumidor precisaria ser (também) protegido contra o sistema comercial tradicional à medida que não oportuniza o direito de opção por um produto sustentável oriundo de um mercado justo. Como se colocou acima, o mercado tradicional é oriundo das forças econômicas de países ditos centrais e de Corporações Transnacionais, situações que fazem do consumidor um mero joguete.

Perceba-se que o Brasil, além de outros países latino-americanos, desenvolve sua política de comércio exterior por intermédio das contingências de mercado, de sistema caracterizado por estrutura administrativo-legal variável segundo a política conjuntural momentânea em relação às demandas internacionais. Em que pese a necessidade de adaptações à realidade extremamente dinâmica do mundo dos negócios, não são raras as determinações casuísticas na ordenação institucional do sistema comercial.

O sistema brasileiro de comércio exterior está, hodiernamente, institucionalizado conforme as disposições da Organização Mundial do Comércio - que caracterizam aquilo que se chama de Free Trade - segundo apreciado, pelo Congresso Nacional e aprovado, pela Câmara de Deputados em 7 de dezembro de 1994, seguido da aprovação do Senado Federal em 15 de dezembro de 1994. O resultado da Rodada Uruguai do GATT/1947, destacando o Tratado de criação da OMC, prevendo a data de 31/12/1994, foi internalizado, no Brasil, pelo Decreto ${ }^{\circ}$ 1.355 de 30 de dezembro de 1994, que promulgou a Ata Final que incorpora os resultados da Rodada Uruguai de Negociações Comerciais Multilaterais do GATT. Esse é o regramento mestre do comércio internacional brasileiro e semelhante de outro países latinos. Além disso, não se deve esquecer da influência que também exercem outros organismos do sistema financeiro internacional, a exemplo do Fundo Monetário Internacional e do Banco Mundial nas políticas nacionais.

Cumpre igualmente lembrar que a globalização não representa um fenômeno que recebe impulsos somente do mercado, mas, das políticas públicas que estimulam a integração 
entre os agentes econômicos na maximização dos lucros. Com isso, resultam tensões de caráter econômico, social e político, com nítida transferência (ou perda) de poder do Estado para as relações negociais. A vulnerabilidade desse processo, ao final, não se restringe às economias, mas, aos consumidores que se submetem sem a devida precaução aos comandos do mercado.

Uma possível resposta ao fenômeno da divinização do mercado, por outro lado, não consiste na renúncia ao mercado. Van Der Hoff $(s / d)$ esclarece que não há como ser contra o mercado, mas, tão somente criar consciência que no mercado atual se corre perigo.

\begin{abstract}
A providência que aparentemente regula tudo rumo ao bem comum morre por completo quando vemos que o bem comum não acontece. É por isso que o Mercado Justo é um Mercado de regulação: pagamento devido conforme o trabalho, ser dono sobre o produto até o consumidor, produzir coisas que necessitamos para viver bem e saudável e dar novamente ao consumidor a liberdade de tomar decisões próprias e justas no mercado. (VAN DE HOFF, $s / d$ )
\end{abstract}

Diante do mercado que não recebeu limites do Estado, emerge a mobilização da sociedade civil para articular-se contra o sistema por intermédio das redes de colaboração solidária. Dentre as Teorias de Rede existentes que podem explicar o fenômeno referido, utilizou-se a Teoria de Rede de Colaboração Solidária apresentada por Euclides Mance (2002, 2014a; 2014b) e a Teoria da Sociedade em Rede sustentada por Imannuel Castells (2006; 2011). As propostas aventam possíveis formas por intermédio das quais a sociedade consegue se organizar para viabilizar um retorno às trocas mercantis sustentáveis. Perceba-se que o Fair Trade, enquanto fenômeno, criou um cenário capaz de competir com o neoliberalismo e com as forças consumistas que lhe são características (isso no âmbito do multilateralismo capitaneado pela OMC). Trata-se, em síntese, de nítido contramovimento neoliberal e opção justa às trocas mercantis. (STELZER; GONÇALVES, 2015a)

Segundo Mance (2014b), a organização de estratégias de colaboração solidária com a capacidade de expandir novas relações sociais de produção e consumo é um fenômeno emergente, "difundindo uma nova compreensão de sociedade, em que o ser humano, considerado em suas múltiplas dimensões, pode dispor das mediações materiais, políticas, educativas e informativas para realizar eticamente a sua singularidade, desejando e promovendo a liberdade dos demais."

A sociedade em rede, em termos simples, é uma estrutura social baseada em redes operadas por tecnologias de comunicação e informação fundamentadas na microeletrônica e em redes digitais de computadores que geram, processam e distribuem informação a partir de conhecimento acumulado nos nós dessas redes. (CASTELS 2006, p. 20). 
Macedo (2015) esclarece sobre Castells, informando que o autor aponta em relação à convergência da evolução social e das tecnologias da informação, que criaram uma nova base material para o desempenho de atividades em toda a estrutura social. Essa base material construída em redes define os processos sociais predominantes, consequentemente dando forma à própria estrutura social. "Estamos em um período de transição: a sociedade conectada em nível global e os Estados organizados em nível nacional, donde se vislumbra que o regramento do tema caminhará para a relativização da soberania dos Estados e para uma governança transnacional, como única forma de tratar conjuntamente os assuntos de interesse global" (CASTELLS apud MACEDO, 2015)

Castells (2011) aposta sua esperança nas redes, pois a sociedade pode escrever novamente sua história. O próprio conceito de Estado-Rede, para o autor, fez que se verificassem mudanças no espaço mundial e a derrocada da estratificação vertical que caracteriza o tempo contemporâneo rumo à horizontalidade das relações econômicas, sociais, tecnológicas, entre outras. Os consumidores, com isso, multiplicam as maneiras colaborativas de trocas, sem se tornarem dependentes dos valores do neoliberalismo e sem ficarem refém das injustas regras que o multilateralismo engendrou.

A formação de redes não tem sede, emerge e ganha força por toda parte de formas variadas. Mance (2002, p. 70) completa: na medida em que se "desencadeiam novos ordenamentos coletivos e democráticos compondo a sinergia das interações, permite-se a emergência de organizações mais complexas, integrando de maneira fecunda movimentos, ações e instituições em campos econômicos, políticos e culturais que estão interpenetrados". Ainda para Mance (2002, p. 71): "quando falamos de uma nova ordem mundial estamos supondo a lógica da diversidade [...] enfatizamos a possibilidade de processos de organização a partir da livre decisão das pessoas de proverem simultaneamente o seu bem-viver e o das sociedades em laços solidários de realimentação."

Quando a referência é Comércio Justo, é precisamente o entrelaçamento hermenêutico que permite o lançamento das suas bases e princípios, situação na qual emergem as regras de respeitabilidade e solidariedade que escoram a rede. "A rede de colaboração solidária está pautada pelo reconhecimento do outro humano, no qual a autopoise retratada por Euclides André Mance se realiza e se alimenta enquanto sistema" (STELZER; GONÇALVES, 2015, p. 278). Os consumidores também podem (devem) pensar por si mesmos, a exemplo do movimento ecológico, das mulheres, da economia solidária, dos refugiados, dos endividados, entre outros. Esse é um momento capital na qual a subjetividade 
alinhou os interesses, permitindo que os consumidores possam se desgarrar do modelo neoliberal, do capital e do interesse privado.

Mance, finalmente, refere-se à teoria da complexidade para exercitar seu raciocínio, pois segundo Morin (2000, p. 91), “a complexidade da relação ordem/desordem/organização surge quando se verifica empiricamente que fenômenos desordenados são necessários em certas condições, em certos casos, para a produção de fenômenos organizados, que contribuem para o aumento da ordem".

[...] a necessidade de pensar em conjunto na sua complementaridade, na sua coerência e no seu antagonismo as noções de ordem, de desordem e de organização obriga-nos a respeitar a complexidade física, biológica, humana. Pensar não é servir às ideias de ordem ou de desordem, é servir-se delas de forma organizadora, e por vezes desorganizadora, para conceber nossa realidade (...) A palavra complexidade é palavra que nos empurra para que exploremos tudo e o pensamento complexo é o pensamento que, armado dos princípios de ordem, leis, algoritmos, certezas, ideias claras, patrulha no nevoeiro o incerto, o confuso, o indizível. (MORIN, 2000, p. 180-181)

Assim sendo, ultimamente foi possível perceber práticas consumeristas e de comportamento que revelam ser um contraponto ao modelo neoliberal que é capitaneado pelos princípio do comércio livre. Tratam-se de ações inspiradas no ser humano como razão central para todas as ações, inclusive comerciais. Com efeito, percebe-se que a acumulação da riqueza e a realização de lucro não podem estar acima do bem-estar.

A crise sistêmica do capitalismo está afetando de maneira intensa aos alcunhados 'países em desenvolvimento' e a cada dia se evidencia mais que o modelo de produção, comercialização, consumo e finanças do sistema capitalista são predatórios, insustentáveis e excludentes. [...] Neste cenário, os países que integram a região da América Latina e Caribe assumem um novo e importante papel na geopolítica da economia mundial e testemunham, também, o auge e crescimento de diversos movimentos associativos e solidários com bases locais e ações globais. (MARISTA, 2015)

Vive-se, portanto, um processo em rede, com novos valores, novos sujeitos e novos relacionamentos jurídicos e morais. Muitos são os exemplos, sendo a denominada Artisans du Monde uma delas. "A Artisans du Monde - AdM importa, a partir de sua central de importação Solidar'Monde, produtos artesanais e alimentícios para comercialização junto ao público francês. A AdM trabalha com 121 grupos de produtores parceiros dentro de 42 países da África, da Ásia e da América Latina." (BADUE, 2005, p. 12) A AdM alcançou tais números pela sua associação em rede independente dos grandes canais de comercialização, "por meio de suas associações regionais, que hoje totalizam na França 157 pontos de venda, animados por mais de 4.500 voluntários e 50 assalariados." (BADUE, 2005, p. 13) Em síntese, assiste- 
se uma globalização diferente dos valores dominantes, ou seja, de bem-viver, não nefasta como a que tem caracterizado o capitalismo. Mais que conhecimento, como sustenta Van Der Hoff (2003, p. 43-44), será preciso sabedoria para seguir em frente e lidar com a sociedade do consumo.

Se o conhecimento humano e os avanços científicos resultam insuficientes para solucionar esse problema, será preciso algo a mais que somente inovação tecnológica e talento. Ao final, tudo dependerá de nossa sabedoria. Sabedoria não é o mesmo mesmo que conhecimento [...] A sabedoria tem a ver com a capacidade humana de estabelecer prioridades, aceitar limites e fazer escolhas. (VAN DER HOFF, 2003, p. 43-44)

A organização das pessoas em rede possibilitou tal realidade e será a partir delas que as relações econômicas e comerciais poderão mudar.

\section{Redes de Comércio Justo na América Latina e a regulamentação do Estado brasileiro}

O neoliberalismo que assolou os países da América Latina e restringiu as políticas públicas de proteção aos consumidores para facilitar a inserção de grupos de interesse privados, ao diminuir a atuação do Estado, incentivou a mobilização do terceiro setor para equilibrar essa equação entre consumo e responsabilidade. Gomes (2015) informa que são muitas as organizações não governamentais que trabalham com o Comércio Justo na América Latina, destacando-se a RIPESS-LAC (Rede intercontinental de promoção da economia social e solidária - Latinoamérica e Caribe); a WFTO-AL (o braço da América Latina do World Fair Trade Association) e o Programa Mercosul Social e Solidário, entre outros, que trabalham, também, na criação de estratégias comuns para a Américal Latina e o Caribe. A autora ainda complementa que a classificação das redes não é tarefa fácil, pois elas têm características bastante diferenciadas, pois algumas são predominantemente políticas, outras produtivas ou comerciais ou uma combinação dessas três, concluindo o seguinte.

Todas as redes da Economia Solidária são, em princípio, redes sociais, cujos vínculos exigem um compromisso coletivo mais amplo, na qual a dimensão econômica é relevante, mas subordinada a dimensões ético-solidárias.[...] As redes econômicas de produção, comercialização e consumo são muito variadas. $\mathrm{O}$ principal elo de união entre elas é o Comércio Justo. Nos últimos anos, numerosas organizações da América Latina têm se dedicado ao desenvolvimento de mercados locais e regionais. (GOMES, 2015) 
É dessas três redes que se parte para descrever o Comércio Justos na América Latina, além da Faces do Brasil que é a rede brasileira, responsável de destaque para coordenar e auxiliar a plataforma brasileira de Comércio Justo.

Do ponto de vista mundial e mesmo na América Latina, a organização mais proeminente é a WFTO-AL, que representa o escritório regional da Organização Mundial do Comércio Justo para a América Latina, atualmente formada por 63 membros provenientes de 13 países. Segundo a WFTO-AL (2015), sua missão consiste em fortalecer as capacidades de incidência, comercialização e monitoramento dos seus membros, promovendo relações de cooperação entre eles e outros atores sociais de forma a contribuir para melhoria das condições de pequenos produtores da América Latina em atenção aos princípios do Comércio Justo. A WFTO-AL pretende ser "reconhecida na região como o interlocutor válido das organizações que promovam um comércio em condições mais justas e como promotor do acesso a mercados, baseado nas capacidades técnicas e empresariais de seus membros, assim como na valorização do patrimônio cultural. Do ponto de vista do consumidor, Ana Asti, ex- presidente da WFTO-AL, esclarece que o "consumidor é o principal ator dessa cadeia produtiva, as empresas produzem o que o consumidor quer comprar. Seja por uma qualidade tangível, como o design ou a cor de um produto, até por uma qualidade intangível, como o fato do produto ser sustentável, respeitar a mão-de-obra [...]" (ECODESENVOLVIMENTO, 2015).

A Rede intercontinental de promoção da economia social e solidária - Latinoamérica e Caribe (RIPESS-LAC) é uma rede que vincula as redes de economia social e solidária em diversas regiões do planeta. Trata-se uma rede de redes, composta de redes intercontinentais RIPESS-LAC (América Latina), RIPESS-EU (Europa), RIPESS-NA (América do Norte), RAESS (África) y ASEC (Ásia) que, por sua vez, reúnem redes nacionais e redes setoriais. "A RIPESS acredita na importância da globalização e da solidariedade com o fim de construir e de reforçar uma economia que coloque as pessoas no centro.[...] O objetivo é satisfazer as necessidades dos indivíduos e das comunidades, ao invés de maximizar as receitas ou ganhos financeiros." (RIPESS, 2015)

Finalmente, o Programa Mercosul Social e Solidário (PMSS) é uma plataforma de trabalho que envolve 17 Organizações Não Governamentais (7 na Argentina, 3 no Brasil, 2 no Chile, 3 no Paraguai e 2 no Uruguai) que atuam no campo do desenvolvimento local, da educação e comunicação popular, da cidadania e da participação e cerca de 200 Organizações Sociais de Base (OS's) desses países (jovens, mulheres, rurais e urbanos). (PARLAMENTODELMERCOSUR, 2015). As atividades do PMSS iniciaram em 2004, 
tendo por objetivo regional "trabalhar conteúdos e ações relativas a dimensão social da integração regional no âmbito do MERCOSUL, contribuindo para o fortalecimento das organizações sociais envolvidas e para a consolidação dos processos de democracia nos países do bloco." (CENTRAC, 2015)

No Brasil, merece destaque como rede de Comércio Justo a Faces do Brasil. Trata-se de uma plataforma constituída por importantes atores do movimento do Comércio Justo e Solidário brasileiro, entre Organizações Não Governamentais (ONGs), articulações de produtores e representantes governamentais, com atuação desde 2001. Segundo a Faces (2015), a sua atuação se direciona à construção e consolidação de um comércio que:

[...] permita o estabelecimento de relações éticas, transparentes e co-responsáveis entre os diversos atores da cadeia produtiva; garanta uma remuneração justa a produtores e produtoras, agricultores e agricultoras familiares, marginalizados pelo sistema convencional das relações comerciais; torne acessível, aos consumidores e consumidoras responsáveis de nosso país, produtos que respeitem nossas diversidades culturais, regionais e históricas, e que promovam uma maior equidade social. (FACES, 2015)

Cumpre perceber que o Faces do Brasil, além de se preocupar com a justiça comercial, interessa-se também pelo consumidor como, aliás, sustenta a Portaria MTE $\mathrm{n}^{\circ}$ 2.060/2014, ao instituir os Princípios e Critérios e os mecanismos de Avaliação da Conformidade da Prática de Comércio Justo e solidário e da Gestão e Organização do Sistema Nacional de Comércio Justo e Solidário (SCJS), em seu artigo 5o, VI - princípio 6: correta e adequada comunicação e informação ao consumidor: a) respeito aos direitos dos consumidores; b) desenvolvimento de atividades educativas relacionadas ao Consumo responsável; c) transparência nas relações de produção, comercialização e consumo; e, d) provisão de informação clara, no estabelecimento comercial ou em site na internet, sobre os produtos e serviços, com controle e informação da origem e qualidade das matérias-primas e insumos utilizados.

Ainda, em semelhante sentido, conforme o Termo de Referência do Sistema Nacional de Comércio Justo e Solidário, documento que reflete as definições do Grupo de Trabalho composto pelo Governo Federal e entidades da sociedade civil, dentre os quais o Faces do Brasil, destaca-se - entre os objetivos - "Apoiar processos de educação para o consumo com vistas à adoção de hábitos sustentáveis e à organização dos consumidores para a compra dos produtos e serviços do CJS". (MTE, 2015)

É importante frisar que, apesar de as dificuldades que cercarão a certificação do Comércio Justo, o Governo Federal disciplinou a questão por intermédio da Portaria MTE $n^{\circ}$ 
2.060/2014, ao instituir os Princípios e Critérios e os Mecanismos de Avaliação da Conformidade da Prática de Comércio Justo e Solidário, além da Gestão e Organização do Sistema Nacional de Comércio Justo e Solidário (SCJS). Isso faz do Brasil o único País a tratar com o ordenamento nacional as diretrizes do Comércio Justo. Nesse sentido, já se tinha o Decreto $\mathrm{n}^{\circ} 7.358 / 2010$, que pouco dizia, mas instituía o Sistema Nacional do Comércio Justo e Solidário (SCJS) e criava sua Comissão Gestora Nacional. Agora, cumpre aguardar a implementação da referida Portaria para verificar sua eficaz atuação.

\section{Conclusão}

O sistema GATT-OMC foi apresentado para corrigir as distorções que levavam ao desvio de comércio, mas, a busca das melhores condições alocativas para os diversos fatores de produção em escala mundial não aconteceram, especialmente para a América Latina que continuou colhendo péssimos resultados, em forma de novo colonialismo. Esse é um pressuposto inevitável e que deve ser explicado para entender o consumismo no continente latino. Dito de outro modo, significa que o consumo exacerbado e sem equilíbrio não é obra do acaso, mas, decorre da ação concertada de grupos de interesse que fazem da sua expansão um planejamento que inclui omissão do Estado e financiamento de compra (superendividamento).

O desenvolvimento sustentável, entretanto, deve avançar rumo a uma governança mundial que possa incluir espaços de decisão que tenham a participação social. Será preciso privilegiar políticas globais que possam viabilizar novas formas de cooperação e que, no âmbito da comercialização, impulsionem o Comércio Justo. A transição para um desenvolvimento sustentável nas esferas ambiental, social e econômica exige reconhecer os benefícios do consumo, mas também seus altos riscos se feito sem controle, de onde se deduzirão as necessárias intervenções, de ordem pública e privada, para mitigar as externalidades negativas dessa realidade.

Do ponto de vista privado, observam-se as formações de rede de colaboração, como forma de proteção e conscientização de larga parcela da sociedade civil que não se curva às tendência de consumo e comercialização desenfreada. Na América Latina, destacam-se no âmbito do Comércio Justo (e da Economia Solidária) a RIPESS-LAC, a WFTO-AL e o PMSS (não se desconhecendo outras tantas reconhecidas redes). No Brasil, destaca-se a Faces do Brasil, reconhecida plataforma de Comércio Justo, integrante da Comissão Gestora Nacional e que perfila organizações da sociedade civil, interessadas em comercialização e consumo 
responsável. As redes de colaboração solidária permitiram fomentar os canais de cooperação da sociedade civil para que o processo obtivesse consistência e continuidade. Assim, ao longo dos anos percebeu-se que esses grupos se fortaleceram e que, atualmente, representam centrais de relacionamento de produtores, consumidores e comerciantes.

No âmbito público, o Estado brasileiro apresenta uma emergente e inédita proposta consubstanciada na normatização do Comércio Justo a partir da Portaria MTE nº 2.060/2014, que instituiu os Princípios, Critérios e Mecanismos de Avaliação da Conformidade da Prática de Comércio Justo e Solidário, e da Gestão e Organização do Sistema Nacional de Comércio Justo e Solidário (SCJS). Nesse caso, tem-se uma política pública em apoio às iniciativas solidárias em movimento de cooperação ao consumo ético.

Nos dois casos supra, optou-se por apresentar o Comércio Justo na qualidade de substrato necessário para se opor ao sistema comercial internacional tradicional e evidenciar necessárias alternativas solidárias, críticas e reflexivas sobre o consumo. Atividades como essas tem permitido que a América Latina se defenda da patologia que resultou o consumismo contemporâneo, assolando o relacionamento social que utiliza produtos e marcas (labels) para, muitas vezes, querer medir o valor do ser humano. Alcançar justiça comercial e consumo responsável é possível, especialmente quando as transações comerciais deixam de ser pautadas pelo egoísmo para se transformar em relação de cooperação e solidariedade.

\section{Referências}

ARBIX, G. Brasil, México, África do Sul, Índia e China: Diálogo entre os que chegaram depois. São Paulo: UNESP, 2002.

BADUE, Ana Flávia Borges et al. Manual pedagógico: entender para intervir. Por uma educação para o consumo responsável e o comércio justo. São Paulo : Instituto Kairós ; Paris: Artisans du Monde, 2005.

BAUMAN, Zygmunt. Capitalismo parasitário. Rio de Janeiro: Zahar, 2010.

Janeiro: Zahar, 2008.

Vida para o Consumo: a transformação das pessoas em mercadorias. Rio de

BRUM, Argemiro J. O Desenvolvimento econômico brasileiro. 22. ed. Ijuí: Unijuí, 1999.

CASTELLS, Manuel. A sociedade em rede: do conhecimento à ação política. Tradução de Rita Espanha et al. s.l.: Imprensa Nacional-Casa da Moeda, 2006.

A era da informação: economia, sociedade e cultura. 6.ed. Tradução de Roneide Venancio Majer. São Paulo: Paz e Terra, 2011. 
CENTRAC. Programa Mercosul Social Solidário. Disponível em:

<http://centrac.org.br/programas/programa-mercosul-social-solidario/> Acesso em: 05/08/2015.

CEPAL (Comisión Económica para América Latina y El Caribe). Pactos para la igualdad: Hacia un futuro sostenible. Santiago, março de 2015. Disponível em: < http://www.cepal.org/publicaciones/search.asp?tipDoc=24\&desDoc=Documentos\%20instituc ionales> Acesso em: 15/07/2015.

COTERA, Alfonso; ORTIZ, Humberto. Comércio Justo. In: CATTANI, A.D. et al. (coord.) Dicionário Internacional da Outra Economia. Coimbra: Almedina, 2009. p. 60-67.

ECODESENVOLVIMENTO. Empresa sustentável. Disponível em: < http://www.ecodesenvolvimento.org/posts/2011/agosto/presidente-da-wfto-na-al-conversasobre-desafios-e\#ixzz3iuhJqUGI> Acesso em: 10/08/2015.

FACES DO BRASIL. Conteúdos. Disponível em: < http://facesdobrasil.org.br/conheca-afaces/motivacao-e-missao> Acesso em: 05/08/2015.

FAJARDO, Elias. Consumo consciente, comércio justo. Rio de Janeiro: Senac Nacional, 2010.

FAJNZYLBER, Fernando. Oligopólio, empresas transnacionais e estilos de desenvovimento. Disponível em: < http://www.cebrap.org.br/v2/files/upload/ biblioteca_virtual/oligopolio_empresas_transnacionais.pdf > Acesso em: 23/07/2015.

FRETEL, Alfonso Cotera; SIMONCELLE-BOURQUE, Eloïse. O comércio justo e o consumo ético. Rio de Janeiro: DP\&A; Fase, 2003.

GOMES, Rosemary. A Economia Solidária na América Latina e no Caribe. Disponível em: < http://facesdobrasil.org.br/ponto-de-vista/a-economia-solidaria-na-america-latina-e-nocaribe> Acesso em: 12/08/2015.

INFOMONEY, 2015. As dez tendências de consumo da América Latina para 2015. Disponível em: <http://www.infomoney.com.br/minhas-financas/consumo/noticia/ 3843642/dez-tendencias-consumo-america-latina-para-2015> Acesso em: 10/08/2015.

LIPOVETSKY, Gilles. Os tempos hipermodernos. São Paulo: Barcarolla, 2004. MACEDO, Caio Sperandéo de. Sociedade em rede e cidadania. Disponível em: $<$ http://ambito-juridico.com.br/site/?n_link=revista_artigos_leitura\&artigo_id=13851\& revista_caderno=9> Acesso em: 07/06/2015.

MANCE, André Euclides. Redes de Colaboração Solidária: aspectos econômicosfilosóficos, complexidade e libertação. Petrópolis, RJ: Vozes, 2002.

Redes de Colaboração Solidária. Disponível em: <http://www.solidarius.com.br/mance/biblioteca/redecolaboracao-pt.pdf > Acesso em: $12 / 05 / 2014 a$.

Teorias de Rede: Introdução Conceitual e Elementos Organizativos. 
Disponível em: <http://redeescoladegoverno.fdrh.rs.gov.br/ upload/1367354901_ ARTIGO \%20REDE.pdf> Acesso em: 11/07/2014b.

MARISTA. Movimento de economia solidária latino americana se reunirá no Brasil. Disponível em: <http://marista.edu.br/ims/2012/04/12/movimento-da-economia-solidarialatino-americana-se-reunira-no-brasil/> Acesso em: 10/08/2015.

MENDES, Zilda; : FERREIRA, Gleriani Torres Carbone. Negócios internacionais e suas aplicações no Brasil. 2.ed. São Paulo: Almedina Brasil, 2013.

MORIN, Edgar. Ciência com consciência. Rio de Janeiro: Bertrand, 2000.

MTE (Ministério do Trabalho e Emprego). Termo de Referência do Sistema Nacional de Comércio Justo e Solidário. Disponível em:

<http://portal.mte.gov.br/data/files/8A7C816A3ADC4075013AFECE06F969A4/Termo_Refe rencia_SNCJS.pdf> Acesso em: 08/08/2015.

PARLAMENTODELMERCOSUR. Programa Mercosul Social e Solidário. Disponível em: $<$ http://www.parlamentodelmercosur.org/innovaportal/file/7829/1/acuerdo-pmssparlasur.pdf> Acesso em: 10/08/2015.

PORTALECOD. Empresas sustentáveis. Disponível em: <http://www.ecodesenvolvimento.org//> Acesso em: 05/08/2015.

PRATA, Lizete; MUNDARÉU. O que é comércio justo? Disponível em: < http://www.mundareu.org.br/portal/index.php/comercio-justo/ > Acesso em: 22/06/2015.

RIPESS (Rede intercontinental de promoção da economia social e solidária). Quiénes somos. Disponível em: < http://www.ripess.org/quien-somos/?lang=es> Acesso em: 13/07/2015.

SCHNEIDER, Johann Wolfgang. Relatório da Pesquisa mundial de Comércio Justo atualização 2010. Disponível em: <http://www.sebraemg.com.br/atendimento/ bibliotecadigital/documento/Cartilha-Manual-ou-Livro/Relatorio-da-Pesquisa-Mundial-deComercio-Justo-2010> Acesso em: 11/05/2015.

STELZER, Joana; GONCALVES, Everton das Neves. Fair Trade em redes de colaboração solidária: possibilidades comerciais justas em um emergente espaço transnacional. In: MACEDO, Paulo Emílio Vauthier Borges de; VIANNA, Bruno (Orgs.). Direito Internacional II; pp. 269-297. Disponível em: < http://www.conpedi.org.br/> Acesso em: 07/06/2015a.

Da tripla dimensão do comércio mundial: multilateralismo, regionalismo e Fair Trade. In: SILVEIRA, Vladmir Oliveira; SILVA, Karine de Souza; ANGELIN, Rosangela. (Org.). Direito Internacional. pp. 258-285. Disponível em: < http://www.conpedi.org.br/> Acesso em: 11/06/2015b.

UNCTAD (UNITED NATIONS CONFERENCE ON TRADE AND DELOPMENT). Draft São Paulo Consensus. Disponível em: <http://www.unctadxi.org/templates/startpage_4.aspx /downloads>. Acesso em: 14/07/2015a. 
. The Spirit of São Paulo. Disponível em: <http://www.unctadxi.org/templates /startpage_4.aspx/downloads>. Acesso em: 14/07/2015b.

VAN DER HOFF, Frans. El corazón del comercio justo. México: manuscrito, $s / d$.

VAN DER HOFF, Frans; ROOZEN, Nico. Comercio Justo: la historia detrás del café Max Havelaar, los bananos Oké y los tejanos Kuyichi. Tradução de Michel Janssen. Amsterdam: Van Gennep, 2003.

WFTO (World Fair Trade Organization). About WFTO. Disponível em: <http://www.wfto.com/> Acesso em: 07/03/2014. 